\title{
Meta
}

Journal des traducteurs

Translators' Journal

FITCH, Brian T. (1988): Beckett and Babel: An Investigation into

the Status of the Bilingual Work, Toronto, Buffalo, London, University of Toronto Press, 242 p.

\section{Catherine Mavrikakis}

Volume 36, numéro 4, décembre 1991

URI : https://id.erudit.org/iderudit/003607ar

DOI : https://doi.org/10.7202/003607ar

Aller au sommaire du numéro

Éditeur(s)

Les Presses de l'Université de Montréal

ISSN

0026-0452 (imprimé)

1492-1421 (numérique)

Découvrir la revue

Citer ce compte rendu

Mavrikakis, C. (1991). Compte rendu de [FITCH, Brian T. (1988): Beckett and

Babel: An Investigation into the Status of the Bilingual Work, Toronto, Buffalo,

London, University of Toronto Press, 242 p.] Meta, 36(4), 664-665.

https://doi.org/10.7202/003607ar d'utilisation que vous pouvez consulter en ligne.

https://apropos.erudit.org/fr/usagers/politique-dutilisation/ 
- FITCH, Brian T. (1988): Beckett and Babel: An Investigation into the Status of the Bilingual Work, Toronto, Buffalo, London, University of Toronto Press, 242 p.

Beckett, traducteur de Beckett, est-il encore Beckett? C'est par cette boutade que l'on pourrait résumer les questions que soulève l'ouvrage de Fitch sur le statut de ce qu'il appelle la «Self-Translation» dans l'œuvre de l'écrivain Beckett. Fitch part du constat d'une occultation par la critique beckettienne de ce qui fait la singularité même de l'œuvre de Beckett depuis les années quarante à savoir son aspect bicéphale, son bilinguisme acharné. «For there does not exist, to my knowledge, any other modern author who has systematically written the whole of his work in two different languages." Cette exemplarité des textes de Beckett explique en partie le silence des commentateurs, mais ce silence peut être aussi interprété comme l'une des conséquences inhérentes à la logique de l'œuvre de Beckett. En effet, si Beckett crée une œuvre à double-voix, qui porte en elle sa propre chambre de résonance, il n'en reste pas moins que chaque texte forme une entité et est autonome quant à sa réception. Les œuvres de Beckett, celles en français aussi bien que celles en anglais, ne renvoient jamais de façon manifeste à leur fantôme dans l'autre langue; leurs titres parfois ne se donnent même pas comme l'écho lointain de leur double: je pense ici, à la suite de Fitch, au Dépeupleur qui a pour faux jumeau anglais The Lost Ones. Beckett traducteur se métamorphose très vite en Beckett écrivain en deux langues. Pourtant, pour celui ou celle qui s'intéresse aux conditions de production des textes, force est de constater que l'acte de création chez Beckett passe par une traduction désirée et nécessaire de son œuvre vers une autre langue. Et ceci même si la traduction pour Beckett était, de son propre aveu, une tâche pénible qu'il détestait entreprendre. Ainsi, et Fitch le fait très bien remarquer, l'œuvre de Beckett se propose comme une traduction vers une langue idéale, et le texte anglais, comme le texte français, ne sont que les possibles de cet idéal inatteignable et qui ne peut se faire entendre que dans la dualité des langues, que dans l'entre-deux de deux langues. Pour Fitch, Beckett refuse «l'intime bien-être d'une langue» et ses textes sont toujours irrémédiablement 
attirés par l'altérité. L'œuvre bilingue de Beckett met au jour le désir de (re)formuler dans un langage second le geste créateur qui était présent à l'origine du texte dans sa première version. La traduction devient ici répétition (reformulation et préparation au sens théâtral) de l'acte de création. Elle est cosubstantielle à l'écriture. Elle est écriture. Mais est-elle encore traduction?

Fitch avec beaucoup de brio et de minutie, à travers un parcours de textes anglais et français, montrera que la «Self-Translation» chez Beckett ne peut se réduire à la traduction telle qu'on la pense, peut-être de façon simpliste, habituellement. Les notions d'original et de copie se trouvent déplacées, car la copie devient un Beckett original. Le texte premier, qu'il soit français ou anglais (Beckett écrivait la première version dans l'une ou l'autre langue sans raison apparente) n'est jamais pour Beckett un texte canonique, mais appelle sa recomposition, son passage vers l'altérité. Pourtant, malgré cet appel de l'autre du texte, ce double travail de l'écriture, Fitch ne voit pas dans le texte second un développement, un éclaircissement du texte-source, pas plus qu'il ne relève dans le texte-cible une tentative de concentration, de reformulation reserrée, épurée, du texte-source. Pour Fitch, la tendance à l'abstraction de l'auteur, la longueur des textes, l'emploi de certains mots, l'omission d'autres mots ne sont que le produit de la langue dans laquelle s'incarne le texte et non le produit du statut d'original ou de copie de ce même texte. «The identity of the language in question clearly appears to be more important than its status as source-language or target-language as far as the transition between the first and the second versions of the work is concerned.» Il faut conclure de là pour Fitch, à une non-spécificité du texte traduit dans l'œuvre de Beckett, et bien voir le deuxième texte comme une création à partir d'un premier jet qui aurait la particularité d'être écrit dans l'autre langue de Beckett. La notion de traduction est évincée et est réduite à celle de la reformulation d'un premier manuscrit. L'œuvre de Beckett est une œuvre bilingue qui met en scène le processus de la traduction tout en le faisant sans cesse avorter.

Le travail de Fitch élargit l'horizon sur la pensée de la traduction en liant celle-ci à la création, mais en même temps il tente de délimiter l'espace de la traduction qu'il oppose à celui de la «Self-Translation». C'est à une reformulation de notions que nous convie Fitch, à une relecture de l'œuvre de Beckett dans la perspective du bilinguisme. En cela l'ouvrage de Fitch est un ouvrage majeur pour les théories de la traduction et de la littérature. 